\title{
Common bile duct stones are mainly brown and associated with duodenal diverticula
}

\author{
O Sandstad, T Osnes, V Skar, P Urdal, M Osnes
}

\begin{abstract}
This study investigated the composition of common duct gall stones from 61 patients, aged 49-94. The stones were collected endoscopically with a dormia basket after endoscopic papillotomy. The cholesterol content was measured both by infrared spectroscopy (mean 29\%, range 0-99\%) and enzymatically (mean $23 \%$, range $0-96 \%)$. The results of the two measurements showed good correlation $\left(r^{2}=0.92\right)$, indicating that cholesterol can be adequately measured enzymatically. Most of the stones were pigment stones. When examined by infrared spectroscopy, 44 stones $(72 \%)$ contained less than $50 \%$ cholesterol (mean $4 \%$, range $0-23 \%$ ). The bilirubinate content in these stones was $56 \%$, range $12-100 \%$. Forty two of these stones were brown stones, and only two were black stones. Pigment stones were associated with juxtapapillary diverticula $(p<0.01)$. It was found that brown pigment stones were the commonest symptomatic bile duct calculi in the patients studied, who are representative of a Western population.

(Gut 1994; 35: 1464-1467)
\end{abstract}

Gall stones have a prevalence of $10-30 \%$ in the normal population, ${ }^{1-4}$ and increase with age. Most gall stones are asymptomatic, but symptomatic stones in the common duct, either 31 January 1994 migrated from the gall bladder or formed in the common duct, ${ }^{5}$ always require treatment to prevent and relieve stasis and infection.

The main components of gall stones are cholesterol and bile pigments. Seventy to 90 per cent of gall stones obtained at cholecystectomy from patients in a Western society are cholesterol stones, consisting of more than $50 \%$ cholesterol. ${ }^{267}$ Pigment stones can be classified visually as black stones, associated with haemolysis, or brown stones, which are thought to result from infection and stasis. ${ }^{8-10}$ Stones in the common duct are often brown pigment stones. ${ }^{11-13}$ There has been no material published, however, on the composition of stones extracted endoscopically.

The aim of this study was to determine cholesterol and bilirubinate content in endoscopically obtained gall stones, and to describe the patient population with common bile duct stones in a tertiary care endoscopy unit. We decided to compare the results of infrared spectroscopy with those of an enzymatic assay to simplify future measurement of cholesterol content. We also wanted to explore our previous finding that duodenal diverticula predispose to common bile duct stones, 1415 with regard to the type of stone.

\section{Methods}

During the years 1987-90 common bile duct stones were collected endoscopically after papillotomy in 61 patients. Mean age of the patients was 74 years (range 49 to 94 ). Thirty four were women (mean age 75 ) and 27 men (mean age 74). All were Norwegian, apart from one woman of oriental origin. Eight had previously been treated with a partial gastrectomy ${ }^{16}$ and 10 had had a previous cholecystectomy. The sample population was representative of patients investigated for common bile duct stones in our department as these have a mean age of 75 years, $56 \%$ are women and $15 \%$ have previously been treated with a partial gastrectomy. None of the patients included were known to suffer from haemolytic disease, chronic pancreatitis or chronic liver disease. One gall stone was examined from each patient.

The presence of duodenal diverticula was sought and noted before cannulation of the papilla of Vater. All stones were caught in a dormia basket in the common bile duct. The stones were stored at $-20^{\circ} \mathrm{C}$ until analysis.

Before analysis the stones were dried in a vacuum oven for 10 hours and weighed. A representative part, either the whole stone or a cross section of the stone was selected, crushed, and $1 \mathrm{mg}$ was prepared with $200 \mathrm{mg}$ $\mathrm{KBr}$ for infrared spectroscopy. ${ }^{17} 18$ The
Figure 1: Twelve stones with increasing amount of cholesterol. The result of the infrared spectroscopy cholesterol analysis, the enzymatic cholesterol analysis, and the infrared spectroscopy bilirubinate analysis, all as a per cent of dry weight is shown to the left of each stone. One of these stones, left column, second from top, was classified as a black pigment stone.
Accepted for publication

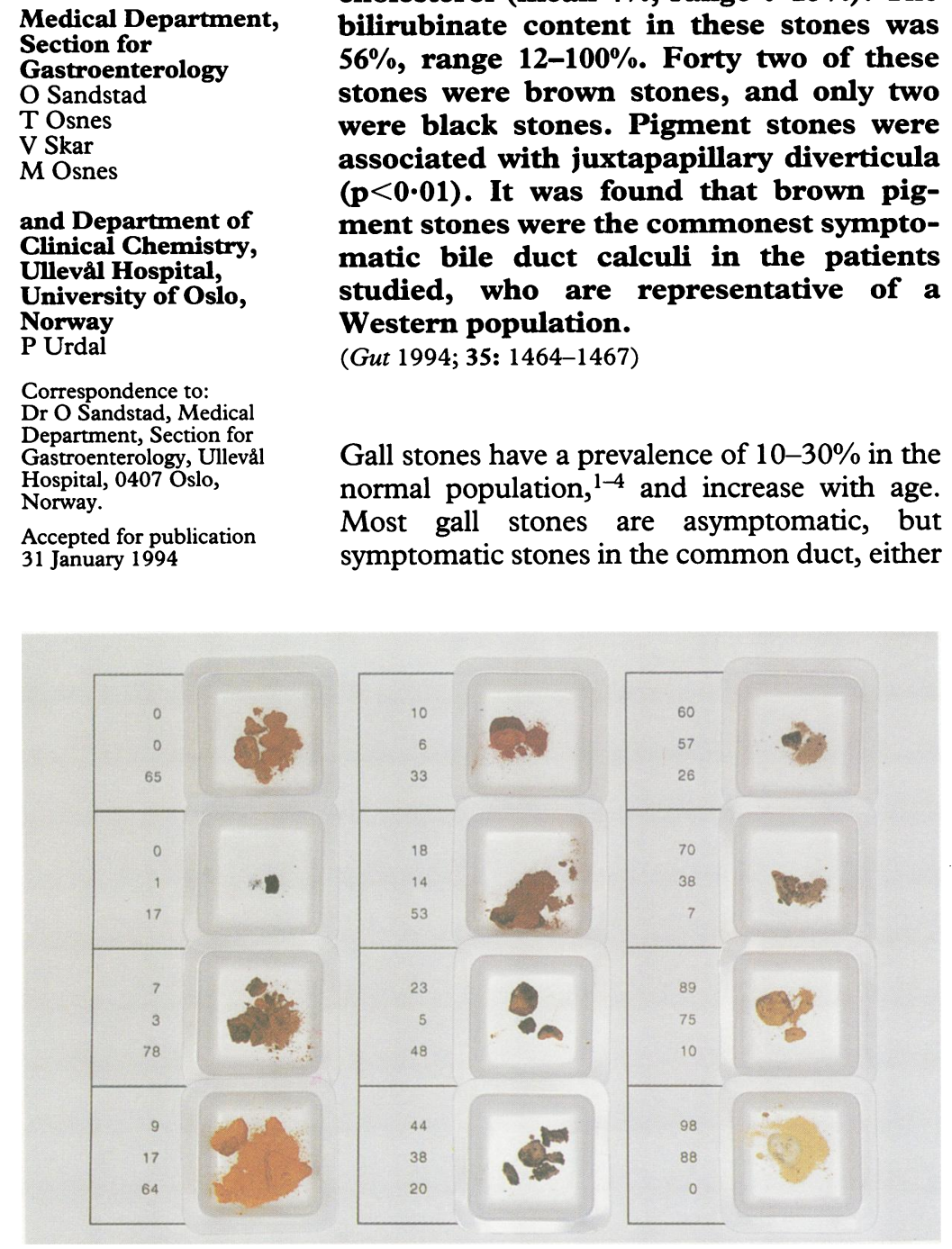




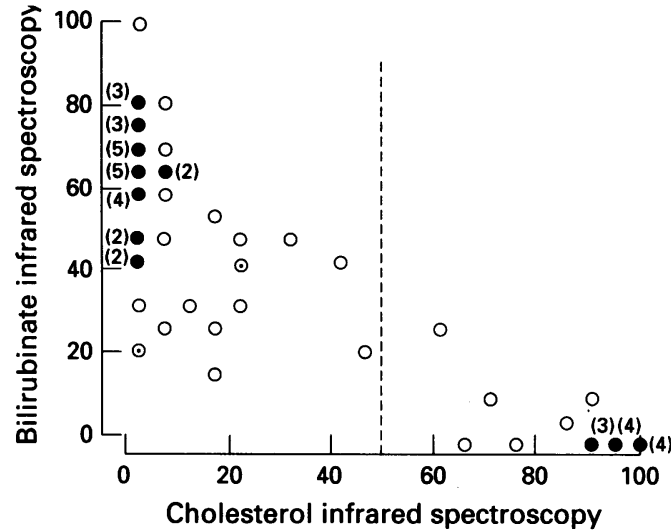

Figure 2: Content of cholesterol and bilirubinate as estimated by infrared spectroscopy, per cent of dry weight. Filled circles represent overlapping measurements and the figure in parentheses shows the number. Dotted line shows cut off value for cholesterol stones. The two black pigment stones are circled.

infrared spectra, Nicolet FT-IR 25 (Nicolet Instrument Corp, Madison, WI), of the stones were compared with those of $1 \mathrm{mg}$ pure cholesterol (Sigma, IL, USA) or bilirubinate. ${ }^{19}$ Several wavelengths were tried before the wavelength for measurement of cholesterol content was chosen. They all gave similar results, and the wavelength $1055 \mathrm{~cm}^{-1}$ was chosen. Contributing to our choice of wavelength was that at about $3400 \mathrm{~cm}^{-1}$, which was the wavelength used by Trotman et al, ${ }^{19}$ problems of interference with hydroxyl groups and amines were to be expected. For bilirubinate analysis the wavelengths 1662 and 1622 $\mathrm{cm}^{-1}$ were chosen for quantitation. ${ }^{817}$ A $5 \mathrm{mg}$ sample was taken from each stone and analysed enzymatically ${ }^{20}$ for its cholesterol content. This assay was performed without knowledge of the infrared spectroscopy results. The stones were classified as cholesterol stones if the infrared spectroscopy measured $>50 \%$ cholesterol. Stones with $<50 \%$ cholesterol content were assumed to be pigment stones. Pigment stones were classified as brown or black according to visual appearance. ${ }^{11} 21$

Results are presented as mean and range. The $\chi^{2}$ test was used to test differences between groups.

\section{Results}

Most stones were brown, earthy, and easily crushable. By infrared spectroscopy we found the 61 stones to contain mean $30 \%$ cholesterol (range 0-99\%), and by the enzymatic assay, $25 \%(0-96 \%)$. The bilirubinate content was $41 \%(0-100 \%)$. In Fig 112 stones with varying cholesterol content can be seen. Figure 2 shows the results of infrared spectroscopy.

TABLE I Characterisation of patients according to stone type

\begin{tabular}{lllll}
\hline & $\begin{array}{l}\text { Cholesterol } \\
\text { stones } \\
(n=17)\end{array}$ & $\begin{array}{l}\text { Brown pigment } \\
\text { stones } \\
(n=42)\end{array}$ & $\begin{array}{l}\text { Black pigment } \\
\text { stones } \\
(n=2)\end{array}$ & $\begin{array}{l}\text { Total } \\
(n=61)\end{array}$ \\
\hline Female/male & $10 / 7$ & $23 / 19$ & $1 / 1$ & $34 / 27$ \\
Juxtapapillary diverticula & 2 & 22 & 2 & 26 \\
Previous gastrectomy & 2 & 6 & 0 & 8 \\
Cholecystectomy & 3 & 7 & 0 & 10 \\
Cholecystectomy $>$ 2 years & 2 & 5 & 0 & 7 \\
\hline
\end{tabular}

${ }^{\star} \mathrm{p}<0.01$.
Cholesterol stones were defined as those containing more than $50 \%$ and pigment stones as those containing less than $50 \%$ cholesterol respectively. Using this definition 44 stones were of the pigment type. By visual evaluation two stones were black pigment stones. An identical result was achieved by three of the investigators independently. Forty two stones were brown, earthy, and easily crushable. Table I gives demographic data with regard to type of stone. A significant association $(p<0.01)$ was found between juxtapapillary diverticula and pigment stones.

Figure 3 shows the results of the enzymatic cholesterol analysis and the relation between cholesterol content estimated enzymatically and by infrared spectroscopy. Of the 61 stones, 59 were categorised similarly by both methods as either cholesterol or pigment stone.

Eight of 51 patients with the gall bladder intact had no stones in their gall bladder (Table II).

The age distribution (Fig 4) shows the type of stone in different age groups. Cholesterol stones were more frequent in patients below 70 (9 of 17) and pigment stones more frequent above 70 years ( 35 of $44, \mathrm{p}<0 \cdot 05$ ).

\section{Discussion}

In this paper we report the composition of gall stones found in the common duct in patients treated endoscopically. We found that $28 \%$ of the gall stones were cholesterol stones, 3\% were black pigment stones, and 69\% were brown pigment stones. Although no previous study has focused entirely on stones extracted endoscopically, this result is in accordance with the current authoritative view. ${ }^{1022}$ Nevertheless, some review articles fail to make the distinction between stones in the gall bladder and the common bile duct. ${ }^{23} 24$

These patients represent a small proportion of patients treated endoscopically in our hospital. About 100 patients with choledocholithiasis are treated in our department each year. For most patients, however, it is not possible both to clear the common duct and to take the stone out with the endoscope. We

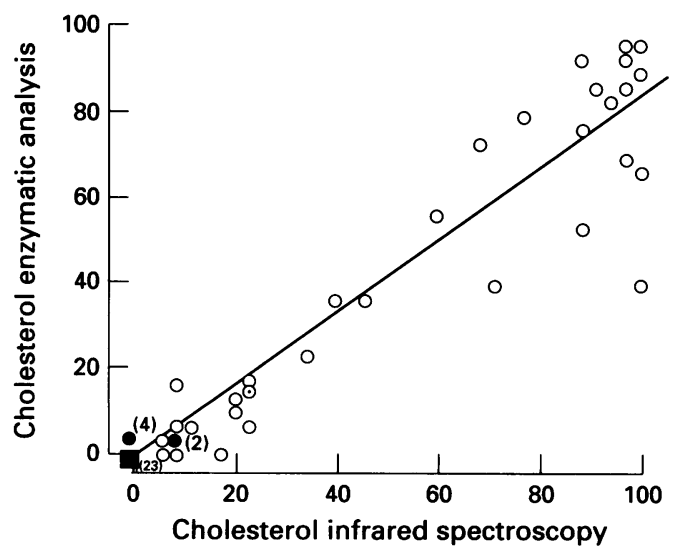

Figure 3: Content of cholesterol as measured enzymatically and by infrared spectroscopy. $y=0.82 \times-0.33, \mathrm{r}^{2}=0.92$. Filled circles represent overlapping measurements and the figure in parentheses shows the number. One black pigment stones is circled, the other is included in $\mathrm{\square}$, which represents 23 stones. 
TABLE II Type of stone in the common bile duct and gall bladder status

\begin{tabular}{lcclc}
\hline & $\begin{array}{l}\text { Cholesterol } \\
\text { stones }\end{array}$ & $\begin{array}{l}\text { Brown pigment } \\
\text { stones }\end{array}$ & $\begin{array}{l}\text { Black pigment } \\
\text { stones }\end{array}$ & Total \\
\hline Cholecystectomy & 3 & 7 & 0 & 10 \\
No gall bladder stone & 3 & 5 & 0 & 8 \\
Cholecystolithiasis & 11 & 29 & 2 & 42 \\
Sludge only & 0 & 1 & 0 & 1 \\
Total & 17 & 42 & 2 & 61 \\
\hline
\end{tabular}

believe no selection bias has taken place, and the equal rate of gastrectomy, and the similar sex and age distribution support this.

It has been shown that patients with duodenal diverticula often have pigment stones. ${ }^{18}$ This condition can be overlooked and it is often not reported. In our study 26 patients $(43 \%)$ had juxtapapillary diverticula. This is in agreement with a recent retrospective study from France, ${ }^{25}$ which reports that $40 \%$ of endoscopy patients with stones in the common bile duct have juxtapapillary diverticula.

Our material consisted of stones collected after endoscopic papillotomy. Most younger patients with common bile duct stones have their stones removed by conventional surgery. As cholesterol stones are more common among younger patients, ${ }^{112126}$ this would indicate that we might have found more cholesterol stones if we had included common bile duct stones treated surgically. Our data confirmed the findings that pigment stones are a feature of older age. Our material is quite small, however, and the association was not very strong.

No systematic investigations for liver disease and haemolysis were undertaken, but none of the patients had clinically known haemolytic or chronic liver disease. Haemolytic disease is rare in Norwegians, and the finding of only two patients with black stones confirms that chronic liver disease and haemolysis is of little importance in our material.

Previous studies suggest that patients treated with a partial gastrectomy run a higher risk of gall stone disease. ${ }^{27-29}$ These stones are generally multiple and small, and possibly of the pigment type. We found that six of eight stones from patients with a previous gastrectomy were pigment stones. This is in concordance with our material as a whole, and does not explain the comparatively high proportion of pigment stones in this study.

Primary common duct stones, recurring

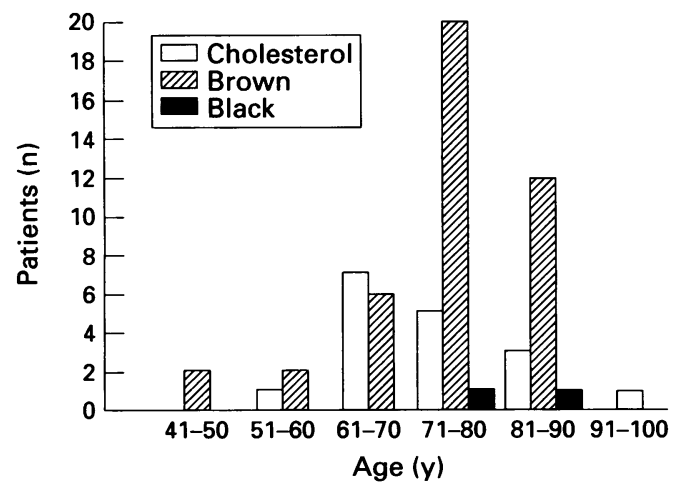

Figure 4: Number of cholesterol, brown, and black pigmen stones at varying age. There were in total 17 cholesterol stones, 42 brown, and two black pigment stones. after cholecystectomy are often brown pigment stones. ${ }^{12}$ In our study three of 10 stones recurring after cholecystectomy were cholesterol stones. One of these had been overlooked at surgery and was removed two weeks later. One was a typical cholesterol stone removed three years after cholecystectomy (the stone in the right lower corner of Fig 1). The last one was removed seven years after cholecystectomy. Diverging results from infrared spectroscopy and enzymatic analysis of cholesterol may be the results of different layers in this stone.

It could be speculated that the stone type influences the possibility of losing the stone during the extraction procedure. Cholesterol stones are often smoother and harder. Pigment stones, on the other hand, are softer, and tend to break down when caught in a stone basket. Some stones were lost, which means that the real percentage of pigment stones might have been even higher.

The enzymatic assay introduced by Wei et $a l^{20}$ provides a simple and more accessible method for quantification of cholesterol content in gall stones. As in the original study, we found it reliable when compared with the more time consuming and less available infrared spectroscopy.

In many of the stones the main component was neither cholesterol nor bilirubinate. This was not unexpected, as other investigators have found stones with up to $67 \%$ of unidentified material, ${ }^{12}$ even after having measured phosphate, carbonate, palmitate, and calcium in addition to cholesterol and bilirubinate. The wide distribution of cholesterol content may also be a feature of brown common duct stones, as these seem to be the result of precipitation of several different components.

Brown pigment stones were until recently thought to be a rare disease in Western countries. Malet et al ${ }^{12}$ found, however, that a significant proportion of common duct stones in the USA were brown pigment stones. Such stones are probably the result of stasis or infection, or both. This can result from duodenal diverticula, which in this study showed a strong correlation with pigment stones. Duodenal diverticula may lead to growth of $\beta$-glucuronidase producing bacteria $^{30}$ and subsequent deconjugation of bilirubinate glucuronides, which leads to pigment precipitation and stone formation.

In conclusion we have shown that brown pigment stones are the commonest stones causing symptomatic bile duct obstruction in a Western population and that cholesterol content of common bile duct stones can adequately be measured enzymatically.

Kjell Windsland, Centre for Industrial Research, Oslo, Norway, performed the infrared spectrophotometry. This work was financially supported by the Anders Jahres Fund.

1 Torvik A, Høivik B. Gallstones in an autopsy series Incidence, complications, and correlations with carcinoma of the gallbladder. Acta Chir Scand 1960; 120: 168-74.

2 Friedman GD, Kannel WB, Dawber TR. The epidemiology of gallbladder disease: observations in the Framingham study. F Chronic Dis 1966; 19: 273-92.

3 Heaton KW, Braddon FEM, Mountford RA, Hughes AO, Emmett PM. Symptomatic and silent gall stones in the community. Gut 1991; 32: 316-20. 
4 Bates T, Harrison M, Lowe D, Lawson C, Padley N. Longitudinal study of gall stone prevalence at necropsy. Gut 1992; 33: 103-7.

5 Saharia PC, Zuidema GD, Cameron JL. Primary common duct stones. Ann Surg 1977; 185: 598-602.

6 van Erpecum KJ, Henegouwen GPvB, Stoelwinder B, Stolk MFJ, Eggink WF, Govaert WHA. Cholesterol and pigment gallstone disease: comparison of the reliability of three bile tests for differentiation between the two stone types. Scand $\mathcal{F}$ Gastroenterol 1988; 23: 948-54.

7 Vitetta L, Sali A, Chou ST, Fleming H, Little P, Elzarka A. Gallstones at autopsy and cholecystectomy: a comparative Gallstones at autopsy and cholecystectom
study. Aust NZ f Surg 1988; 58: 561-8.

8 Soloway RD, Trotman BW, Maddrey WC, Nakayama F Pigment gallstone composition in patients with hemolysis

9 Cahalane MJ, Neubrand MW, Carey MC. Physicalchemical pathogenesis of pigment gallstones. Semin Liver Dis 1988; 8: 317-28.

10 Crowther RS, Soloway RD. Pigment gallstone pathogenesis: from man to molecules. Semin Liver Dis 1990; 10: 171-80.

11 Bernhoft RA, Pellegrini CA, Motson RW, Way LW. Composition and morphologic and clinical features of common duct stones. Am 7 Surg 1984; 148: 77-85.

12 Malet PF, Dabezies MA, Huang G, Long WB, Gadacz TR Soloway RD. Quantitative infrared spectroscopy of common bile duct gallstones. Gastroenterology 1988; 94: common

13 Whiting MJ, Watts JM. Chemical composition of common bile duct stones. Br F Surg 1986; 73: 229-32.

14 Osnes M, Lotveit T, Larsen S, Aune S. Duodenal diverticula and their relationship to age, sex and biliary calculi. Scand $f$ Gastroenterol 1981; 16: 103-7.

15 Skar V, Lotveit T, Osnes M. Juxtapapillary duodenal diverticula predispose to common bile duct stones. Scand f Gastroenterol 1989; 24: 202-4.

16 Osnes M, Rosseland AR, Aabakken L. Endoscopic retrograde cholangiography and endoscopic papillotomy in patients with a previous Billroth-II resection. Gut 1986; 27: $1193-8$.
17 Edwards JD, Adams WD, Halpert B. Infrared spectrums of human gallstones. Am $\mathcal{f}$ Clin Pathol 1958; 29: 236-8.

18 Lotveit T. The composition of biliary calculi in patients with juxtapapillary duodenal diverticula. Scand $\mathcal{f}$ Gastroenterol 1982; 17: 653-6.

19 Trotman BW, Morris TA, Sanchez HM, Soloway RD, Ostrow JD. Pigment versus cholesterol cholelithiasis: identification and quantification by infrared spectroscopy. Gastroenterology 1977; 72: 495-8.

20 Wei JS, Huang HM, Shyu WC, Wu CS. Simple enzymatic determination of total cholesterol in gallstones. Clin Chem 1989; 35: 2247-9.

21 Trotman BW, Soloway RD. Pigment gallstone disease: summary of the National Institutes of Health - internummary of the National Institutes of Health

22 Carey MC. Pathogenesis of gallstones. Am F Surg 1993; 165: 410-9.

23 Paumgartner G, Sauerbruch T. Gallstones: pathogenesis Lancet 1991; 338: 1117-24

24 Johnston DE, Kaplan MM. Pathogenesis and treatment of gallstones. N Engl f Med 1993; 328: 412-21.

25 Hagège H, Berson A, Pelletier G, Fritsch J, Choury A, Liguory $\mathrm{C}, e t$ al. Association of juxtapapillary diverticula with choledocholithiasis but not with cholecystolithiasis. Endoscopy 1992; 24: 248-51.

26 Trotman BW. Pigment gallstone disease. Gastroenterol Clin North Am 1991; 2: 11 1-26.

27 Anderson JR, Ross AHM, Din NA, Small WP. Cholelithiasis following peptic ulcer surgery: a prospective controlled study. Br F Surg 1980; 67: 618-20.

28 Lorusso D, Misciagna G, Noviello MR, Tarantino S Cholelithiasis after Billroth II gastric resection. Surgery 1988; 103: 579-83.

29 Pezzolla F, Lantone G, Guerra V, Misciagna G, Prete F, Giorgio I, et al. Influence of the method of digestive tract reconstruction on gallstone development after total gastrectomy for gastric cancer. Am 7 Surg 1993; 166: 6-10.

30 Skar V, Skar AG, Bratlie J, Osnes M. Beta-glucuronidase activity in the bile of gallstone patients both with and without duodenal diverticula. Scand $\mathcal{f}$ Gastroenterol 1989; 24: 205-12. 